\title{
The reform of the teaching mode of Applied Optics curriculum and analysis of teaching effect
}

\author{
Yu Ning, Zhongjie Xu, Dun Li, Zilun Chen, Xiangai Cheng, \\ et al.
}

Yu Ning, Zhongjie Xu, Dun Li, Zilun Chen, Xiangai Cheng, Hairong Zhong, "The reform of the teaching mode of Applied Optics curriculum and analysis of teaching effect," Proc. SPIE 10452, 14th Conference on Education and Training in Optics and Photonics: ETOP 2017, 1045264 (16 August 2017); doi: $10.1117 / 12.2269906$

SDIE Event: 14th Conference on Education and Training in Optics and Photonics, ETOP 2017, 2017, Hangzhou, China 


\title{
The Reform of the Teaching Mode of Applied Optics Curriculum and Analysis of Teaching Effect
}

\author{
Yu Ning ${ }^{1,2,3}$, Zhongjie $\mathrm{Xu}^{1,2,3,4}$, Dun $\mathrm{Li}^{1,2,3}$, Zilun Chen ${ }^{1,2,3}$, Xiangai Cheng ${ }^{1,2,3,4 *}$, Hairong Zhong ${ }^{1}$ \\ ${ }^{1}$ College of Optoelectronic Science and Engineering, National University of Defense Technology, \\ Changsha 410073, Hunan, China \\ ${ }^{2}$ Hunan Provincial Key Laboratory of High Energy Laser Technology, Changsha, Hunan, China \\ ${ }^{3}$ Hunan Provincial Collaborative Innovation Center of High Power Fiber Laser, Changsha, Hunan, \\ China \\ ${ }^{4}$ State Key Laboratory of High Performance Computing, National University of Defense Technology, \\ Changsha, Hunan, China
}

\begin{abstract}
Military academies have two distinctive characteristics on talent training: Firstly, we must teach facing practicability and connecting with academic frontier. Secondly, the bachelor's degree education and the military education should be balanced. The teaching mode of basic curriculum in military academies must be reformed and optimized on the basis of the traditional teaching mode, so as to ensure the high quality of teaching and provide enough guidance and help for students to support their academic burden. In this paper, our main work on "Applied Optics" teaching mode reform is introduced: First of all, we research extensively and learn fully from advanced teaching modes of the well-known universities at home and abroad, a whole design is made for the teaching mode of the core curriculum of optical engineering in our school "Applied Optics", building a new teaching mode which takes the methods of teaching basic parts as details, teaching application parts as emphases, teaching frontier parts as topics and teaching practical parts on site. Then combining with the questionnaire survey of students and opinions proposed by relevant experts in the teaching seminar, teaching effect and generalizability of the new teaching mode are analyzed and evaluated.
\end{abstract}

Keywords: Applied Optics, teaching mode reform, military academies

\section{INTRODUCTION}

Compared with the general higher education, military academies have two distinctive characteristics on talent training: Firstly, we must teach focusing on practicability. Basic course teaching not only needs to highlight the practicality of knowledge for practical demands, but also should associate with academic hot spot content to improve the forwardness of knowledge. Secondly, military cadets are required to complete both the bachelor's degree education and the military education, course arrangement is busier during study period, leisure time after class is less as well. The teaching mode of basic curriculum must be reformed and optimized deeply on the basis of the traditional teaching mode, so as to ensure the high quality of teaching and provide enough guidance and help for students to support their academic burden.

The teaching mode is not only a stable and concise theoretical framework of teaching structure, but also contains a concrete and operable way of teaching activities to guide people to explore and strengthen the teaching design as a whole, to study the optimal combination of teaching process ${ }^{[1]}$. The teaching mode is able to reflect the teaching philosophy, teaching objectives and teaching strategies for a curriculum of an university, also guides the teaching practice directly ${ }^{[2,3]}$.

"Applied Optics" is the core compulsory curriculum of optical engineering in our school, plays a key role in cultivating students' engineering qualities, it is of great significance to improve the teaching quality of this curriculum in the whole specialized teaching. In this paper, we take "Applied Optics" as an example to introduce the main work of our school on basic curriculum teaching mode reform.

14th Conference on Education and Training in Optics and Photonics: ETOP 2017, edited by Xu Liu,

Xi-Cheng Zhang, Proc. of SPIE Vol. 10452, 1045264 • ( ) 2017 ICO, IEEE, OSA, SPIE

CCC code: $0277-786 X / 17 / \$ 18 \cdot$ doi: $10.1117 / 12.2269906$ 


\section{THE COMPARATIVE STUDY OF TEACHING MODES OF BASIC CURRICULA AT HOME}

This paper investigates the teaching systems and small class teaching methods of many foreign universities which take the leading position in the field of optical engineering teaching and scientific research, these universities are: University of Arizona, Stanford University, University of Rochester, Cambridge University and Queen Mary University of London, Zhejiang University, Huazhong University of Science and Technology, Beijing Institute of Technology at home.

Four outstanding young teachers of our teaching team have been selected one after another to track the whole curriculum teaching processes of the same or similar specialties in Stanford University, University of Rochester and University of Bath, summed up a number of research and analysis reports.

Through the comparative study, we find that foreign elite schools and domestic colleges and universities have a lot in common in the arrangement of teaching contents and the use of teaching methods, such as: the grasp of key and difficult teaching points, promoting the research-based teaching philosophy, using multimedia networks and other modern teaching methods, combining theoretical learning with practice courses and taking flipped classroom to teach. However, foreign colleges and universities pay more attention to contact with multiple ideas, open up personal visions and exercise comprehensive abilities on the basis of specialized quality training, it specifically reflects on the emphases of classroom teaching and teaching counseling two aspects.

Cambridge University, for example, the teaching of relevant courses has following two distinctive features: firstly, the information in class is large. Teaching contents of one class in Cambridge are approximately equivalent to two classes in domestic colleges and universities, it is hard to fully digest teaching contents only by using class time. So Cambridge attaches great importance to after-class counseling, every undergraduate student has a full mentor, there is fixed time for them to meet every week, the instructor will supervise students to study personally. Besides, each group is equipped with a counseling graduate who mainly takes charge of homework explanation, answering questions and related extensions; secondly, the homework assignment level is high. Every topic need to be thought seriously even wrestled to be answered, and the same knowledge will appear only once, the knowledge coverage of exercises is complete ${ }^{[4]}$.

Most of the domestic colleges and universities adopt the class-dependent education mode, extracurricular supplementary teaching more becomes a mere formality. Through extensive researches we find that learning in foreign colleges and universities is just a form, extracurricular supplementary teaching is the key to ensure the quality of teaching students.

\section{THE WHOLE DESIGN OF THE TEACHING MODE OF "APPLIED OPTICS" CURRICULUM IN MILITARY COLLEGES}

On the basis of learning advanced teaching modes of relevant curricula of elite schools at home and abroad, the shortcomings of the "Applied Optics" curriculum system of optoelectronic engineering specialty in our school are analyzed, and a small class teaching mode with military school characteristics and "Applied Optics" curriculum characteristics is created ${ }^{[5]}$.

\subsection{Teaching methods and teaching means}

Contents of "Applied Optics" curriculum are divided into two parts: bases and applications. In order to inspire students' interests of learning, an introductory lesson is added_ approaching "Applied Optics". The introductory lesson is the first lesson of the new curriculum learning, it' also the most important lesson. By learning the introduction, students understand why to learn, what to learn, how to learn and other issues.

For the basis part, the teaching method of "teach+self-study+practice+test" is adopted. The concrete actions in two class hours of one class are as follows: 1)the teacher goes over the outline of contents of this lesson, then leads some questions

$\left(10^{\prime}\right)$; (2) students learn by themselves under the problem guidance $\left(35^{\prime}\right)$; (3)students operate optical instruments during classes $\left(10^{\prime}\right)$; (4)the teacher stresses the emphases and answer some difficulties (35');(5)teaching contents are summarized and inspected (10').Reference to relevant foreign classical textbooks, like "Geometrical Optics and Optical Design" and "Optics System Design", etc., primary concepts and theories are further refined and explained, the theoretical foundation of students is reinforced during limited class time.

For the application part, the teaching method of "self-study+teach+practice+flip" is used.The concrete actions in two class hours of one class are as follows:(1)students preview before class under the problem guidance (10');(2)the teacher 
goes over teaching contents under the problem guidance $\left(45^{\prime}\right)$; (3)students operate optical instruments during classes ( $10^{\prime}$; (4)a flipped classroom is set, students deliver reports in groups $\left(30^{\prime}\right)$; (5)other groups ask questions about the report and the teacher gives comments $\left(15^{\prime}\right)$.Arrange teaching contents which have timeliness, perspectiveness and practice, and integrate the latest scientific achievements with class. For example, when the topic of telescopes is taught, an example of a strong laser emission system is introduced as a teaching case, and the teaching method of "flipped classroom" is used to discuss "the working principles and working characteristics of optical telescopes and radio telescopes". When teaching the topic of infrared optical systems, a seminar "comparative analysis of the working principles and working characteristics of infrared thermal imagers and low light night vision devices" is set up. When explaining the microscope topic, aseminar "super-resolution fluorescence microscopy technology" is opened.

The frontier part is taught as topics. Practical problems with research or inquiry are designed to cultivate the innovative spirits and practical abilities of students. (1)seven projects tightly associated with topics are added: comparative analysis of the working principles and working characteristics of optical telescopes and radio telescopes (echoes the topic of telescopes); super-resolution fluorescence microscopy technology (echoes the topic of microscope topic); analysis of the imaging principles of light field cameras (echoes the topic of cameras); analysis of 3D movie technology (echoes the projection system topic);comparative analysis of the working principles and working characteristics of infrared thermal imagers and low light night vision devices(echoes the topic of infrared optical systems); analysis of blue LED technology and its application(echoes the topic of laser optics); research of the applications of traditional fibers and photonic crystal fiber(echoes the topic of fiber optics).(2) Seminars are added, every group need to produce a thematic report according to the topic appointed by the project, but the report focus can be chosen by themselves, then one student of the group is selected to give explanation on the podium, other groups ask questions and discuss on the topic.

For the part closely associated with the practicability, the method to teach on site is taken. The practical teaching joint teaching and training of optoelectronic equipment is carried out. Through teaching on site, students get chances to contact with the equipments at close range. Through operating optoelectronic equipment on site, students can further experience the application of "Applied Optics" curriculum in actual equipment, it is helpful to consolidate the textbook knowledge accepted passively and stimulate the learning enthusiasm of students.

\subsection{Diversified teaching resources}

On the basis of exploring the new method of teaching actively, teaching counseling and communication after class are strengthened significantly. An after-class counseling team composed of young teachers and Ph.D. students is organized, every instructor is responsible for one group(3 4 students in every group), to provide students with extra-curricular guidance and assistance. What's more, diversified teaching resources are built, material object demonstration, exchange platform on WeChat and teaching resources on the internet are used to help students to digest teaching contents which they don't master in class, concrete actions conclude the following several aspects:

(1) Add some optical instruments to the class teaching: miniature projectors, small telescopes, microscopes, fiber optic faceplate and other classroom physical demonstration equipment, to enhance students' interests in learning and improve teaching effects;

(2) Invite famous teachers from other schools to our classroom to give lectures, for example, "Typical Optical System Design and Aberration Analysis" is taught by professor Li Xiaotong and professor Cen Zhaofeng from Zhejiang University, the chance to communicate with famous teachers face to face and learn from them is provided for students;

(3) By virtue of the excellent platform belonging to the optoelectronic sub-commission of the commission of teaching instruction, a personal teaching space of "Applied Optics" curriculum is built up, courseware, projects, video public classes and past examination questions and answers of "Applied Optics" curriculum are uploaded.

\section{ANALYSIS OF TEACHING EFFECTS OF THE NEW TEACHING MODE}

Through the teaching practice of two semesters and the questionnaire survey of students, organizing "Exploration and Practice of the New Classroom Teaching Mode of 'Applied Optics'" feature teaching seminar and fully listening to the opinions and suggestions proposed by relevant experts in the teaching seminar, the following conclusions are tentatively drawn.

The new teaching mode of "Applied Optics" brings a fresh feeling for the schedule, it is easy to understand, strict in logic, strong in practice and with great enlightenment. The curriculum combines military school characteristics and 
curriculum characteristics, integrates the latest scientific achievements with class, has perspectiveness and practice; students learn by themselves under the guidance of problems, so that the study of students is targeted, which vastly improves the study efficiencies and self-study abilities of students; by setting up topic discussions and projects nearly connected with curriculum contents and using the method of flipped classroom to exchange and discuss, the abilities to analyze problems deeply and refine scientific thoughts of students are trained; learn from advanced teaching experience abroad, pay attention to the extra-curriculum counseling, organize an after-class counseling team composed of young teachers and Ph.D. students and diversify the teaching resources, create conditions for students to better grasp curriculum contents.

\section{CONCLUSION}

In this paper, we combine the teaching purpose and actual situations of our school, take "Applied Optics" as an example to do some exploration and practice on basic curriculum teaching mode reform. By making a whole design for the teaching mode of "Applied Optics", a new teaching mode which takes the methods of teaching basic parts as details, teaching application parts as emphases, teaching frontier parts as topics and teaching practical parts on site is adopted to reinforce the specialty foundation of students, improve the comprehensive learning abilities of students, lead students to contact the frontiers of science and enhance students' knowing of practical equipments. According to the comprehensive assessment, it is recognized that the new teaching mode is suitable for small class teaching, can be extended to teaching practice of curricula which have strong applicability.

Funding. The teaching and research project of the education and teaching of photoelectric specialty in National Universities

\section{REFERENCES}

[1] Joyce, "Teaching mode", Seventh Edition, translation by Jianhua Xing, China Light Industry Press, 5-8 (2009).

[2] Margarita Pavlova, "Teaching and learning for sustainable development: ESD research in technology education", International journal of technology and design education, 23(3) (2013).

[3] Jiawen Xu, Xiangai Cheng, Hairong Zhong "Reflection and practice about Teaching Modes of Applied Optics Course," Journal of Higher Education Reaearch, 39(1), 115-120,(2016).

[4] Kang Ji, "Analysis and Research on the development of Applied Optics Education," Electronic world, 4445, 183-184 (2014).

[5] Zefeng Wang, Xiangai Cheng "A study on the teaching model of military academy undergraduate course," Higher education research,60-62,(2012) 